\title{
A brief reflection about the challenge of criminal intelligence against organized crime
}

\begin{abstract}
Traditionally the fight against organised crime has been characterised by the absence of a minimum reflection about the offensive and reactive operations strategies normally used, accumulating a number of significant strategic errors in the confrontation against the organised crime phenomenon. To counteract this situation, the application of criminal intelligence capabilities appears an interesting opportunity to provide a better understanding of the organised criminal phenomenon and get more expectations of success in the ultimate neutralization of the phenomenon.
\end{abstract}

Keywords: organised crime, criminal intelligence, strategic intelligence, criminology, security
Volume 5 Issue 2 - 2017

\author{
Daniel Sanso Rubert Pascual \\ Security and Defense Studies Center, University of Santiago de \\ Compostela, Spain
}

Correspondence: Daniel Sanso RubertPascual, Security and Defense Studies Center, University of Santiago de Compostela, Spain,Email daniel.sanso-rubert@usc.es

Received: June 20, 2017 | Published: June 28, 2017

\section{Index}

\section{Same questions about the exploitation of criminal intelligence in the fight against transnational organized crime. What is it, and what is it useful for? and the future challenges and opportunities}

Traditionally, the fight against organised crime has been characterised by the supremacy of action in detriment of well thought out strategies ${ }^{1,2}$ Gilmour and France, accumulating a plurality of significant strategic errors in the confrontation against the organised crime phenomenon ${ }^{3}$ Boer, 2013. Similarly, using strategic and intelligence terms in the response to organised crime was the subject of criticism, arguing against the squandering of expensive and limited means to address the problem of the states' own internal security (Sansó-Rubert, 2010).In trying to analyse criminal organisations as a whole, there is a wide variety of types that could be configured as a continuum. In the extremes one finds from small associations with slightly weak and unstable links to established structures, to consolidated structures that are notoriously well rooted and dangerous. The scene forms a ragtag group of organisations whose structure, discipline, internal rules, division of roles, idiosyncrasy, illegal activities and therefore, hazards, represent a plurality of combinations ${ }^{4}$ that are generally ignored and, to date, little studied.

The characterisation of organised crime as a phenomenon that faces a constant evolutionary process in order to adapt to the environment in which it intends to carry out its illegal activities so as to avoid a loss of competitiveness and effectiveness, ${ }^{5}$ has led to the configuration of an international scenario that is favourable to its interests, displaying a cross-cutting nature and a great capacity for criminal diversification. The successful use of every opportunity to thrive and grow rich, coupled with a growing commitment to transnationalization, has hindered the fight against organised crime, with limited success achieved in global terms, differentiating in geographical terms the successes that have been achieved in specific areas (European Union, United States...), against the failure or the achievement of pyrrhic victories in areas such as Africa or some parts of Latin America like in the Central American Northern Triangle (Honduras, Guatemala and El Salvador) ${ }^{6,7}$

Accordingly to what has been expressed so far, twenty-first century policing, as already shown, cannot be exclusively restricted to the reactive repression of crime and the maintenance of public order. We must overcome this anachronistic view. The institutional systems that act against crime have traditionally been based on reaction and not anticipation. Following this approach, the objective of policing has always been reported crime and not its potential existence, ensuring the enforcement of criminal laws by repressing offenders. However, the reality requires a change of view in the fight against crime, focusing not on the conduct and the investigation and arrest of the perpetrators, but on the assessment and management of the threat of crime which in itself is a behavior factor or element that can lead to damage and criminal liability, but by definition has not yet made such damage. ${ }^{1}$ This reality creates tension in the structures and police procedures because both the penal system and the police system were originally conceived as instruments of reactive action before the criminal damage had been perpetrated.

If traditionally the reactive orientation of the security forces has allowed for the strategically-oriented model, based in the response capability against crime, at present several factors are affecting police efforts towards a model of prospective strategy in which the effort is focused not on the reaction towards the commission of crime, but in anticipating and taking measures to prevent such events from occurring. Having lost the initiative to address the proliferation of organized crime in its early stages, now that there's a will to react against its consolidation and expansion, it turns out that, against a backdrop of a multi-faceted and ever-evolving security scenario, state bureaucracies remain largely constrained by stagnant functional schemes. The security agencies have become fossilized against a criminality that exploits the advantages provided by globalization, asymmetric conflict and its lack of ethical or moral restrictions. This "functional ballast", added to the State's own territorial and jurisdictional limitations, have hindered the institutional response so far, conferring a bigger advantage to organized crime. 
Consistent with this descriptive framework, the need to address an ever more sophisticated form of crime should stimulate a strong commitment towards specialization and diversification. This specialization, in turn, inevitably demands overcoming the traditional and clearly inadequate paradigms, opting instead for innovative responses that must be necessarily transversal and integrational. ${ }^{8} \mathrm{All}$ this without belittling the reactive activity of the State. Although its effectiveness against organized crime has been weakened, it remains an excellent tool for providing citizen security and prosecution of crime in general.

We are witnessing therefore a change in thinking on the role of public safety, making way for a prospective strategy model in which the institution's efforts are focused not so much in restoring rights, but in preventing criminal behavior from occurring. Thus, the new criminal strategic model is oriented towards the anticipation to said criminal behavior. While the reactive model functionally links effectiveness and deterrence, the greater the repressive activity, the greater the deterrence, the anticipatory model assumes a different view that doesn't focus so much on the behaviors and perpetrators but on the assessment and management of a specific criminal threat. It therefore seems more appropriate in this area to point to a redefinition of the security model and the fight against crime, so that the result is an effective and useful combination of reactive and preventive initiatives. Against this background, one must reflect on what role criminal intelligence should play, and what are the characteristics that give it its own identity.

It should be emphasized that criminal intelligence is only one type of intelligence used to obtain, evaluate and interpret information and disseminate the necessary intelligence to protect and promote national interests of any nature (political, commercial, corporate) against organized crime, in order to prevent, detect and enable the neutralization of those criminal activities, criminal groups or individuals who by their nature, magnitude, dangerousness, etc, endanger, threaten or violate the constitutional order, as well as the rights and fundamental freedoms. Similarly, its usefulness resides in its use as an element of successful analysis of public policies and decisions in confronting organized crime. It allocates intelligence capabilities for the analysis of State governance and institutional strengthening to be able to discern well in advance how certain decisions about the management of public affairs (resources, goods and services) permit or facilitate the operations and functioning of organizations operating outside the law, so as to identify the implications of the decisions taken, and it uses preventive schemes to prevent the inadvertent strengthening of organized crime.

Having said that, reality forces us to deal with the prevailing uncertainty concerning the delimitation of the concept of criminal intelligence. Every day we hear about the mixing up of criminal and police intelligence and criminal intelligence and criminal or police investigation. Moreover, this confusion is also played out to a lesser extent in other disciplines such as criminology, criminalistics, criminal statistics, criminal phenomenology and all sorts of methodologies that are valid for the generation of useful empirical knowledge, to obtain a cognitive approach on the criminal phenomenon. Consequently, to speak about criminal intelligence and its powers and purpose is not "per se" a particularly peaceful discourse between doctrine and intelligence operators. Therefore, it is important to develop some thoughts on how to distinguish one tool from another, since the differentiating elements have enough identity to enable us to establish a clear distinction.

As a starting point, we should review the common origin of both police and criminal intelligence. Not surprisingly, the police traditionally have had the duty of dealing with any criminal event as guarantor of the internal security of states. A police intelligence developed by and for the provision of policing and whose purpose is to provide the decision-maker, be it a police officer or a politician, with an informed knowledge for a better management of police resources and to maximize their preventive, proactive and also reactive capabilities, ${ }^{9,10}$ in order to strengthen the protection of public order, social peace and the preservation of coexistence (public safety). In my opinion the turning point that breaks the common identification between both, takes place in the last decades. As shown in the preceding paragraphs in which I address in a brief and concise manner the transformations that have taken place in the current criminal scenario, the phenomenon of organized crime has got an unusual importance to date, requiring an intelligence typology that not only covers roughly part of the functions of police intelligence, but its specificity (specialization) leads to more extensive requirements in view of the increasing complexity inherent to organized crime itself. Not surprisingly, the police themselves have experienced this process of specialization, developing specific units to fight against organized crime. These units even have in some cases subspecialties in terms of geographical areas, types of crime or other circumstances of police interest.

It is in this context that we must locate the blossoming of criminal intelligence, divided almost from its origin from what was considered policing, strictly speaking, and characterized by a set of features among which we can include similarities and dissimilarities in comparison to police intelligence. Criminal intelligence then, not only represents a specific application of the generic capabilities of intelligence, that is, limited to the area of security that deals with organized crime, but one can also identify a progressive specialization of the agencies, services or units dedicated to it. Likewise, there is no doubt today that criminal intelligence is a tool shared by police forces, armed forces, intelligence services and even by private security companies. None of these actors has a monopoly or a leading role in this area of intelligence. This idea help to break the prefabricated link between criminal intelligence and police forces, that it can only be sustained in another one of the greatest misconceptions that hang over criminal intelligence: that its ultimate goal can only be the arrest of criminals (offenders) and therefore, inevitably, their prosecution.

Criminal intelligence, by definition, is not abrogated to a particular entity but, depending on circumstances (administrative and political) it may well be housed in intelligence, either in police units, customs, prisons and even in military organizations. In this regard, one can emphasize that the cross-sectional nature of organized crime itself, makes the attribution of powers and competences to a service or another by virtue of their competence in the exterior or interior area of security, lack any sort of sense. Given the transnationalization of organized crime, the traditional distinction between internal and external security loses its functionality, rapidly blurring the boundaries when we refer to the activities run by criminal organizations. Criminal intelligence operates equally at both poles of security. However, based on the theoretical distribution of security powers among different state actors, internal security has traditionally gone to the 
Police Forces, while the Armed Forces have been responsible for external security. The theory, however, doesn't always conform to reality. Other distinguishing features worth mentioning are the fact that although both police intelligence and criminal intelligence can operate at various levels (operational, tactical and strategic), practical reality seems to reflect different approaches and trends. Thus, police intelligence has a greater success in the operational and tactical levels, while criminal intelligence tends to be confined to the sphere of strategy and prospective, without it meaning that they cannot develop in any of the other dimensions, as in fact they do.

We must emphasize the holistic nature of criminal intelligence, characterized by approaching the analysis and interpretation of an issue or a situation from a multidisciplinary perspective and integrating information from all types of sources. This intelligenceproducing methodology allows us to address the challenges associated with a broad concept of security. It is defined by three basic features: the analysis and interpretation of an issue or a situation from a multidisciplinary approach, the integration of information from all sources and its processing by a team. ${ }^{11}$ This novel way of understanding and working with intelligence fits perfectly with the cross-sectional nature of the criminal phenomenon itself. Criminal intelligence therefore, should be thought of in terms of holistic intelligence by definition. Another conceptual confusion to be considered, especially in Latin America given its political history and institutional approach, is the identification of criminal intelligence with intelligence developed by civilian agencies, to distinguish it from military intelligence. This match between the two intelligences (civil intelligence equals criminal intelligence) doesn't hold up, contributing to distort its proper semantic apprehension.

Similarly, the adoption or not of a vision where crime predominates, allows us to establish differences between criminal intelligence (abstracted from criminal and punitive spheres), and police intelligence, which tends to focus on those areas of reality where the likelihood of criminal conduct occurring is more pronounced. Criminal intelligence, therefore, is not conducted or doesn't establish its priorities and objectives under the type or volume of the crimes. It responds to the interests and goals previously set by the decision maker, who as a consumer of intelligence previously defines the contents of the intelligence product in relation to his/her needs. Instead, police intelligence prioritizes the identification of criminal factors such as places of habitual conflict or what Ericson and Haggerty called the Geography of the problems, ${ }^{12}$ repeat offenders, frequent reproduction of criminal conduct, identification of new criminal methodologies; in short, to obtain, collect and analyze data and information of interest to the police using the intelligence cycle and obtain the resulting police intelligence product on criminals and their activities in order to prevent them from acting. Police intelligence draws its analysis from the study of great volumes of information about crime, ${ }^{13}$ so as to promote law enforcement and the highest yielding preventive and reactive police response. ${ }^{14}$ Intelligence-led policing reformulates the police institution to make it more effective in the exercise of authority and the capabilities assigned to it, maximizing its resources in the fight against crime. ${ }^{9,13,15}$ On the other hand, part of the confusion stems from the identification of criminal intelligence with criminal or police investigation, or also with criminal analysis.

Regarding the first case, criminal intelligence "per se", as opposed to criminal investigation, doesn't do infiltrations, surveillance and monitoring. Its central axis is the analysis of the organized crime phenomenon. The main idea resides in distinguishing the fieldwork of the information gatherer, from the analytical work of the analyst, who remains at a distance from the operational theatre. At the same time, the information being gathered through various methodologies (surveillance and infiltration) can have a dual purpose: to constitute evidence and clues to apprehend the elements responsible for a crime, and their later prosecution inside of typical criminal investigation by police forces (identified as judicial police work). And, at the same time, alternatively, also this information can be used to provide information about the criminal phenomenon, that the intelligence analyst (not the police investigator) will employ in the making of the criminal intelligence product.

Unlike an intelligence analyst, a police investigator is personally involved in the whole process: he/she is directly involved in the collection of data using appropriate techniques and, in turn, analyses the data to determine the criminal charges in order to gather all of it in his/her analysis, whose recipients will be judges and prosecutors. $\mathrm{He} / \mathrm{she}$ ensures the element of evidence and prevents the escape or concealment of the suspects, in time and according to the procedures prescribed in the respective criminal codes. He/she applies all the means and investigation techniques that are needed to recollect the evidence regarding the alleged criminal acts and their perpetrators, in accordance with the appropriate criminal codes. Moreover, the preventive nature of criminal intelligence makes its activity seem permanent. It doesn't react to the commission of a crime (Criminisnotitia) as happens with criminal investigation, but it operates in a constant continuum over any individual, activity or organization that could turn into a future threat or is a risk to security. When intelligence is late, the crime has already been committed. When the intelligence work has been unsuccessful and the criminal act has materialized, it becomes the subject of police investigation and criminal analysis.

While criminal intelligence has a clear preventive character, it tries to provide knowledge to allow the authorities to anticipate and neutralize or dissuade threats, criminal investigation acts in a totally repressive manner, since it only intervenes after a specific criminal act, to identify the perpetrators and to provide legal evidence that enables a criminal prosecution. Therefore, criminal intelligence doesn't essentially pursue the solving of a crime. It doesn't operate in the field of criminal types, but in the vague field of threat, risk and predictive situations. This does not mean that, in certain circumstances, it doesn't require an operationalization of developed intelligence, or at least part of it, to implement a police operation (operational intelligence) for the effective neutralization of the criminal threat, or that during the development of intelligence analysis some elements liable to be used as evidence in a judicial context, appear. In these cases, the dichotomy over the pros and cons of the judicialization of intelligence arises: the evidence given by intelligence experts. An option that awakens an arduous doctrinal and conceptual controversy that for the moment has not been successfully resolved. The motivation to use intelligence as procedural evidence is directly related to the culture of the suppression of evidence and should be understood in terms of exceptionality (ultima ratio). This choice is based on the difficulty of apprehension inherent to the phenomenon of organized crime, sometimes leading to the search for sufficient evidence to secure a conviction over criminal acts that might otherwise prove difficult to prosecute.

This option is not without risks and technical difficulties, given the understandable open reluctance of analysts to expose themselves 
at a trial, especially when the respective legislations rarely include procedurally valid formulas that do not violate the right of defense of the accused and at the same time safeguard the personal safety of the analyst turned expert witness. What is not in doubt, whether one likes it or not, is that the criminal intelligence product may be used, and in fact has been successfully used as evidence (this is a peculiarity of this type of intelligence that aims to replace, where deemed necessary and appropriate, the lack of evidence to neutralize the criminal activity). On the other hand, the confusion with criminal analysis also has no place, since it includes techniques and procedures used to study crime in order to provide law enforcement agencies with useful information designed to encourage the development of knowledge about the criminal environment: identifying areas of criminal risk, modus operandi, new criminal acts, system vulnerabilities to crime, obtaining criminal patterns and the evolution of criminal phenomenology are all among the highlights. ${ }^{9}$ All this based on the simultaneous study of crime in an individual way and as a whole, establishing in turn, comparisons of a different nature (geographical, temporary, statistical...). In short, to know the crime and the environment in which it takes place, its main characteristics, manifestations and effects. To do this it uses different techniques and procedures such as data integration, qualitative analysis, research in problem-solving, creation and interpretation of statistics, time series analysis, demographic analysis, crime mapping, data mining and various methodologies to measure crime. ${ }^{10}$

Even though it is true that criminal analysis generates useful knowledge about crime, it should not be confused with criminal intelligence, because this knowledge in origin and nature is not an intelligence product; ${ }^{10}$ it has not been obtained by applying intelligence processes and its ultimate goal goes no further than to deepen the understanding of a phenomenon, lacking the rest of interrelations one would expect from an intelligence product. Nor should we dismiss this kind of knowledge, but we must see it instead as highly useful for the development of criminal intelligence. Not surprisingly, there are academic disciplines such as criminology and criminal phenomenology, which are intended to study the offense, the offender, the victim and social control, and whose empirical research should definitely be taken into consideration as qualified material (knowledge) for the development of criminal intelligence. Another favorable factor that generates confusion lies in establishing a differentiating element between criminal intelligence and useful information for the prosecution of crime, the exact moment in which knowledge is produced, whether it is before or after the crime. The mistake comes from the way the intelligence cycle has been traditionally understood.

In daily practice it is found that the intelligence cycle phases are not watertight, that between one step and the next step in the process there are communicating vessels, that their actions are repeated, its direction is not as linear as it might initially appear, that its activities take place in an interrelated manner or even simultaneously. This is so, because it is common that data entry occurs incessantly, that the product user changes his/her demands or asks for more intelligence halfway through the process, that the emergence of new data leads to a provisional analysis or that the urgency of a new matter demands that "untreated" information of great interest is provided to the decision makers with few pieces of available data. Therefore, it is necessary to reconsider if the intelligence gathering model is the most appropriate, or if on the contrary, others like the model of intelligence focused on the target are better for the development of intelligence about organized crime, since this continuous feedback of criminal intelligence applying the intelligence cycle generates confusion about the exact phase of the cycle we find ourselves in; whether we are in the development phase of intelligence or whether, on the contrary, we find ourselves caught in a perpetual information gathering phase simultaneous to consecutive criminal investigations: the continuous influx of new data from the commission of crimes generates the erroneous impression that one always arrives too late, resulting in the hindrance of any effort to develop criminal intelligence.

This confusion occurs largely because the data collection phase for the elaboration of criminal intelligence and the information/ evidence gathering phase in police or criminal investigation, on many occasions run simultaneously and share the same goals but have different purposes. This circumstance reproduces confusing episodes of overlapping where it is difficult to discern the boundaries between both, clearly identifying where one begins and the other ends. Setting limits is something that is difficult to carry out, since the very understanding of the complexity of organized crime demands an analysis that combines a macroscopic and contextual view (criminal intelligence), with a microscopic investigation of specific facts (criminal investigation). The collateral issue is that, firstly, the term intelligence cycle has a long tradition and an almost universal and widespread educational use; but on the other hand, it is not an accurate representation of the real and daily operation of the production and dissemination of intelligence.

A proposal that fits with the approach and use of criminal intelligence and could help to overcome the current state of confusion is the intelligence analysis focused on the target. ${ }^{16}$ This model understands the production of intelligence as a networked cooperative process where a collective repository is built (on organized crime relevant to the security of the State), where all participants can obtain the necessary inputs for their work and also contribute their own resources and knowledge. Recalling the diversity of organizations producing criminal intelligence of a varied nature, this methodology enriches the criminal intelligence product from a holistic perspective. The intelligence process focused on the target is described as follows: users who have operational problems consult in the repository the current state of the knowledge about a target (for example a criminal organization dedicated to transnational drug-trafficking) and identify their information needs; the intelligence analysts working with information collectors translate the needs into knowledge pools and information requirements; the collectors get the required information and they incorporate it to the shared repository of information about the target; analysts extract usable intelligence and supply the users and they in turn can add their own contributions about the target to the repository or insert new information needs. Because the perspective that is focused on the intelligence target is more interactive, it allows for a better handling of complex problems, like organized crime, specific criminal markets or activities.

The key to success lies in advancing two complementary and simultaneous lines: understanding a phenomenon while interacting with it through interventions that affect them directly or modify their environment. That is, the combination of criminal intelligence with neutralization operations of a police (criminal investigation) or military nature, which disrupts the activities of organized crime under the prism of target-focused intelligence. This represents a complex 
task, at least for now. The development of strategies and more effective tools to neutralize the criminal activity of transnational organized crime and to promote cooperation and coordination at the national and international levels, should constitute a governmental priority for the $21^{\text {st }}$ century. Initiatives will require changes in attitudes and ways of thinking in the structures of security and intelligence organizations and primarily the relationships between them; in conclusion, it is a must to articulate a true Intelligence Community capable of connecting the entire cast of actors involved in the intelligence cycle, both producers and consumers, managing to incorporate to this community the information that is available throughout the state and social fabric, to put it at the service of security.

Within the list of possible initiatives, criminal intelligence must aspire to something more descriptive than producing reports. To put it simply, strategic analysis, coupled with prospective studies articulate the scrutiny of the criminal reality orientated towards the future. To adopt diagnosis not as an end in itself but as a means to predict future scenarios, ascribe to them probability and desirability so as to be able to design appropriate plans under stated objectives, allowing us to acquire a deep understanding of the etiology of crime and its phenomenology. Also, a good criminal intelligence product not only establishes the current situation of the phenomenon, but also provides explanations for the existence of this phenomenon and establishes possible developments or trends, defining possible or probable scenarios. It also defines the viable alternatives to redirect the situation in the most favorable way towards its eradication and control, and establishes the eventual social and economic costs resulting from the application of such measures. Similarly, criminal intelligence stands out as an ideal tool for developing security strategies to reorganize the procedures and instruments available to governments to tackle crime, and to help redefine the objectives in the fight against organized crime: it establishes policy and plans to implement and help reach the targets; to identify and understand the elements and factors favoring the emergence and expansion of organized crime, paying attention to the appearance of signs and the evolution of risk indicators in order to achieve an early detection before they materialize, and the discovery and identification of anything that might represent a chance of success for organized crime. Therefore, its development confers distinct advantages, allowing us to minimize the impact of crime, especially when the cost of opportunity when making a decision can even be qualitatively more burdensome or create irreparable damage.

To sum up, criminal intelligence represents a range of challenges and opportunities. On the one hand it allows not only a greater and better grasp of the criminal phenomenon across the spectrum, but it also provides an informed knowledge indispensable for the articulation of resources (Formal social control: Criminal, security and defense policies, corrections, legislative, police...) at operational, tactical and strategic levels, designed to offset the criminal risk. Given the magnitude of the threat posed by organised crime, the development of strategies and tools to neutralize organised criminal activity, especially in its transnational dimension, and promote cooperation and coordination at the national and international levels, should constitute priorities for governments in the $21^{\text {st }}$ Century. Therefore, capacity building and the exploitation of criminal intelligence, confers distinct advantages allowing us to minimise the impact of crime especially when the cost of opportunity when it comes to making a decision (and not another) could be qualitatively more burdensome or generate irreparable damage.
To emphasize that in general terms, a good product of criminal intelligence not only describes what the current situation regarding the phenomenon is, but provides explanations on the existence of the phenomenon and establishes possible developments or trends, defining possible and probable scenarios. It also defines the viable alternatives to redirect the situation in a way that can lead to its eradication and control, and establishes the potential and social costs resulting from the application of such measures. In the same way, it allows us to know and analyse the geographical distribution of criminal activity, the territorial concentration of criminal organisations (criminal density), the emergence of new niches of illicit markets, the introduction of new technologies and modus operandi, new products and services, the identification of strategies implemented by criminal structures, the relevant sociodemographic characteristics of members of criminal organisations (nationality, region of origin, ethnicity, family, profession, status as former policemen or former combatants, type of illegal activity that they specialise in...) as well as detecting the rise and fall of criminal organisations. There is a constant dynamic in the criminal world leading to some groups declining and others emerging: the difficult thing for them is to persevere through time. Time will tell whether the fight against organized crime is advancing towards where we want it to go or simply advancing from where we can manage it. The key does not lie in considering what we would like criminal intelligence to be, rather it lies in determining how far we want to exploit its usefulness, to seriously determine its future uses. ${ }^{17-35}$

\section{Acknowledgments}

None.

\section{Conflicts of interest}

The author declares there are no conflicts of interest.

\section{References}

1. Fernando M. Critical analysis of the organized crime threat assessment reports in the European Union (Organized Crime Threat Assessment, OCTA). Royal Elcano Institute, Spain. 2009.

2. Pascual DSR. Criminal intelligence: a strategic choice in security key to the organized crime initiative. In: Fredy RV, editors. Strategic and Prospective Intelligence, South America. 2011;215-238.

3. Felbab Brown V. Modernizing the application of the law. Report 2. Targeted deterrence, selective action, drug trafficking and organized crime: concepts and practices. International Consortium on Drug Policy, Spain. 2013;1-20.

4. Luis C, Andrea GS. Crimen.org: Evolution and keys to organized crime. Planet, Spain. 2010;1-455.

5. Sansó Rubert Pascual D. Transnational organized crime and international security. In: Rodríguez F, Jordán JJ, editors. Security and Defense today. Spain. 2008.

6. Kees K, Dirk K. Armed actors, organized violence and state failure in Latin America: a survey of issues and arguments. Zed Books, UK. 2004.

7. Ashley BN. The Twenty-First Century Expansion of the Transnational Drug Trade in Africa. Journal of International Affairs. 2012;66(1):69-84.

8. Mellón JA, Miratvillas E, Serra del Pino J. From strategic intelligence to proactive intelligence. In: González C, Luis J, editors. Intelligence. Valencia, Spain. 2012;387-409. 
9. Ratcliffe J. Strategic Think bin Criminal Intelligence. The Federation Press, UK. 2009;1-240.

10. Baker TE. Intelligence led policing. Leadership, Strategies and Tactics. Looseleaf Law Pubns Corp, USA. 2009;1-370.

11. Navarro E, Ángel M. Intelligence glossary. Madrid. Ministry of Defense of Spain, Spain. 2007.

12. Ericson RV, Haggerty KD. Policing the Risk Society. Clarendon Press, UK. 1997;1-502.

13. Cope N. Intelligence led Policing or Policing led Intelligence?: Integrating volume crime analysis into policing. BRT J Crim. 2004;44(2):188-203.

14. Tilley N. Problem-Oriented Policing, Intelligence-Led Policing and the National Intelligence Model. Jill Dando Institute for Crime Science, UK. $2003 ; 1-7$.

15. Smith A. Intelligence led policing: International Perspectives on Policing in the $21^{\text {st }}$ Century. International Association of Law Enforcement Intelligence Analysts, USA. 1994;1-20.

16. Clark RM. Intelligence Analysis: A Target-Centric Approach. CQ Press, USA. $2004 ; 1-432$.

17. Pascual DSR. Organized crime and illicit trafficking in light weapons Implications in the field of international security. In Non-state armed actors. Challenges to security, Spain. 2012;177-205.

18. Albanese JS, Das DK. Introduction: a framework for understanding. Organised Crime. World Perspectives, USA. 2003.

19. Enrique AB. Organized crime: criminal, procedural and criminological aspects. Huelva Publications service of the, Spain. 1999;1-406.

20. John A, David R. Networks and network war: the future of terrorism, organized crime and political activism. Alliance, Spain. 2003.

21. Andrea C, Navarro E, Ángel M. Intelligence Services: environment and trends. In: Cussac G, Luis J, editors. Intelligence, Spain. 2012;73-105.

22. Fassone E. The assessment of the evidence in the processes of organized crime. Poder Judicial. 1997;64:113-154.

23. Caparrós F. Organized Crime In: French G, López S, editors. The New Criminal Code: first problems of application, Spain. 1997.
24. Cyrille F. Transnational crime and the role of the United Nations in its containment through international cooperation: a challenge for the $21^{\mathrm{st}}$ century. European Journal of Crime, Criminal Law and Criminal Justice. 2000;8(2):119-127.

25. Diego G. The Sicilian mafia. The private protection business. Fund of Economic Culture,Mexico. 2007.

26. Carlo M. Inside Criminal Networks. Springer, USA. 2009.

27. Julia P, Pascual DSR. A Phenomenological Analysis of Terrorism and Organized Crime from a Comparative Criminological Perspective. Journal of Law and Criminal Justice. 2014;2(2):113-131.

28. Fernández R, Julio J, Pascual DSR. The constitutional appeal to the Armed Forces for the maintenance of internal security. The Latin American case. Mexican Bulletin of Comparative Law. 2010;128:737-760.

29. Paz SG, Isabel. Organized crime. Criminal, procedural, administrative and police aspects. Dykinson / Ministry of the Interior, Spain. 2005.

30. Pascual DSR. Security vs. Freedom: the role of Intelligence Services. In: Joseph M, Felip Sardá, editors. Intelligence and national security: the state of the matter. Spain. 2004;85-112.

31. Pascual DSR. The internationalization of organized crime: analysis of the phenomenon. In UNISCI Discussion Papers 9, Spain. 2005;43-62.

32. Pascual DSR. The role of information in the fight against transnational organized crime. In UNISCI Discussion Papers, 12, Spain. 2006;203-227.

33. Pascual DSR. Globalization and crime: transnational organized crime. In Beyond the State, Spain. 2011;135-157.

34. Pascual DSR. Military participation in the provision of citizen security and its use in the face of the expansion of the organized criminal phenomenon. In International Society in the 21 st Century: New security perspectives, Spain. 2011;221-238.

35. Pascual DSR. Security strategies, organized crime and criminal intelligence: a commitment to the future. In: Rodríguez F, Pascual DSR, editors. Intelligence Issues in Contemporary Society, Spain. 2012;204219. 